\title{
RANCANG BANGUN ALAT UJI LAJU DAN WAKTU PEMBAKARAN PLASTIK PADA ARAH HORIZONTAL
}

\author{
Farit Ardiyanto*, Kaleb Priyanto ${ }^{2}$,Dany Faishal Afif $^{3}$ \\ ${ }^{1}$ Program Studi Teknik Elektronika, Sekolah Tinggi Teknologi "Warga" Surakarta, Indonesia \\ ${ }^{2,3}$ Program Studi Teknik Mesin, Sekolah Tinggi Teknologi "Warga" Surakarta, Indonesia \\ *Email: faried2402@gmail.com
}

\begin{abstract}
ABSTRAK
Penggunaan material plastik dan komposit polimer semakin massif di berbagai aplikasi khususnya industri otomotif. Berbagai rekayasa dan penelitian telah mampu menghasilkan karakteristik mekanis dan fisis material plastik yang mampu menggantikan material logam. Namun demikian, penggunan plastik pada aplikasi dengan resiko kebakaran perlu melalui pengujian hambat bakar. Pengujian tersebut menghasilkan tingkat kemampuan material menghambat laju pembakaran serta penundaan waktu penyalaan api. Metode pengujian tersebut salah satunya diatur di dalam standar UL 94 AVH. Untuk mendapatkan hasil yang akurat serta memberikan kemudahan dalam mengoperasikan, maka perlu dibuat sebuah alat uji laju dan waktu pembakaran plastik pada arah horizontal. Artikel ini membahas proses hingga unjuk kerja alat dengan tetap berdasar pada standar yang diacu. Proses manufaktur alat uji dimulai dengan observasi, pembuatan desain alat dan skematik pemantik otomatis, machining komponen, wiring kelistrikan, perpipaan dukungan gas, assembly, dan finishing. Hasil pengujian menunjukkan bahwa alat uji laju pembakaran ini dapat digunakan secara akurat dan menunjukkan perbedaan laju pembakaran setiap specimen uji dengan material dasar yang berbeda.
\end{abstract}

Kata kunci: uji bakar, horizontal, komposit, polimer.

\section{ABSTRACT}

The use of plastic and polymer composite materials is increasingly massive in various applications, especially the automotive industry. Various engineering and research have been able to produce mechanical and physical characteristics of plastic materials that can replace metal materials. However, the use of plastics in applications with a fire risk needs to go through a combustion resistance test. This test results in the level of material ability to inhibit the rate of combustion and delay the ignition time. One of the test methods is regulated in the UL 94 AVH standard. To get accurate results and provide ease of operation, it is necessary to make a tool for testing the rate and time of plastic burning in the horizontal direction. This article discusses the process to the performance of the tool while remaining based on the referred standards. The test equipment manufacturing process begins with observation, making tool designs and schematic of automatic lighters, machining of components, electrical wiring, gas support piping, assembly, and finishing. The test results show that this combustion rate tester can be used accurately and shows the difference in the combustion rate of each test specimen with different base materials.

Keywords: burning test, horizontal, composite, polymer.

\section{PENDAHULUAN}

Teknologi komposit dan polimer berkembang sangat pesat dalam rangka peningkatan kemampuan material tersebut sebagai alternatif pengganti logam. Namun pada aplikasinya, ketahanan termal polimer masih perlu perhatian khusus untuk mengurangi resiko kebakaran bila akan diterapkan pada konstruksi yang memperhatikan standar keamanan penggunanya. Sebagai contoh, penggunaan material berbasis polimer pada konstruksi kendaraan bermotor seperti gerbong kereta api, pesawat terbang, maupun mobil listrik harus melalui serangkaian pengujian termal untuk menjamin keamanannya. 
Salah satu metode pengujian termal terhadap material berbahan dasar plastik adalah pengujian laju pembakaran specimen horizontal dan waktu penyalaan api sesuai standar UL-94.

Misnon, 2018 melakukan pengujian respon kebakaran berdasarkan standar ASTM D-635 untuk membandingkan Laju pembakaran relatif linier komposit dalam bentuk specimen persegi panjang pada posisi horizontal sehingga menghasilkan data tingkat pembakaran material yang ditentukan dengan rumus:

$\mathrm{V}=60 \mathrm{~L} / \mathrm{t}$

dengan $\mathrm{V}$ adalah laju pembakaran (dalam $\mathrm{mm} /$ menit); L adalah panjang pembakaran (mm); dan t adalah waktu perjalanan api L (mm) [1].

Setyanto et al. 2012 melakukan pengujian sifat mudah terbakar dari sampel yang lolos dari sifat warna dan tembus cahaya berdasarkan standar ASTM D635 dan ASTM D3801 [2]. ASTM D635 adalah standar pengujian untuk laju pembakaran dan/ atau luas dan waktu pembakaran plastik dalam posisi horizontal. Standar tersebut adalah tingkat pengujian terendah bagi spesimen yang mudah terbakar dan padam sendiri. Spesimen dengan ketebalan $3 \mathrm{~mm}$, lebar $13 \mathrm{~mm}$, dan panjang $125 \mathrm{~mm}$ dalam posisi horizontal dibakar di salah satu sisi. Spesimen dikategorikan dalam kelas HB yaitu kelas pembakaran horizontal atau bahan yang mampu padam sendiri bila laju pembakaran 75 $\mathrm{mm} / \mathrm{menit}$ atau lebih rendah [3]. Tingkat yang lebih tinggi dari kelas HB adalah pembakaran vertikal. Standar pengujian tersebut digunakan untuk mengukur karakteristik pembakaran komparatif plastik padat dalam posisi vertikal. Standar pembakaran vertikal dilakukan berdasarkan ASTM D3801 [4].

Pada tahun 2016, Basmal dkk melakukan pengujian ketahanan laju pembakaran terhadap material komposit polyester berpenguat hybrid partikel arang sekam padi dan kalsit. Pengujian sifat kecepatan laju bakar spesimen komposit mengacu ASTM D 635, spesimen diletakkan pada posisi horinsontal pada sebuah penjepit spesimen dan pembakar posisi miring dengan sudut $45^{\circ}$ terhadap spesimen [5]. Selain ASTM D635, standar yang biasa digunakan untuk mengetahui laju pembakaran plastik adalah UL-94. UL 94 AVH Chamber digunakan mengukur sifat pembakaran (setelah nyala api bercahaya) dengan burner (pembakar tirrill H-5025 UL) ketika sampel uji terbakar dalam volume internal ruang $0,864 \mathrm{~m}^{3}$ dan dipasang lampu internal untuk mengamati sifat spesimen dan memiliki bukaan ventilasi dengan kipas emisi untuk menghilangkan gas pembakaran. UL 94-AVH memiliki sistem pemindahan spesimen otomatis untuk melindungi pengguna dari gas berbahaya dan sistem pemindah burner otomatis untuk memenuhi seluruh standar pengujian. Sistem penggerak pembakar otomatis ini memiliki goniometer, sehingga dapat mengubah sudut nyala api ke benda uji $\left(0^{\circ}, 20^{\circ}, 30^{\circ}, 45^{\circ}\right.$, $90^{\circ}$ ). Kotak kontrol dan pengontrol jarak jauh membantu pengguna untuk menangani peralatan ini atau memeriksa setelah waktu nyala api dan setelah waktu nyala selama pengujian dan dapat menyesuaikan sudut.

\section{BAHAN DAN METODE}

Komponen-komponen yang diperlukan dalam pembuatan alat uji rambat bakar plastik adalah case, top plate, base, statif dan clamp, bunsen burner, slider, perangkat sistem pengaturan dan penyediaan gas, perangkat sistem pemantik api. Gambar 1 menunjukkan alat uji hambat bakar plastik yang telah dirakit.

Observasi awal dilakukan terutama untuk menentukan konstruksi dan material yang tepat untuk pembuatan chamber serta desain yang memudahkan operator dalam mengatur spesimen dan nyala api. Dimensi spesimen uji yang sesuai dengan ASTM D635 
ditentukan sebagai berikut: Panjang spesimen $150 \mathrm{~mm}$ (125 mm standar panjang lintasan bakar), lebar spesimen $13 \mathrm{~mm}$, dan tebal spesimen $3 \mathrm{~mm}$.

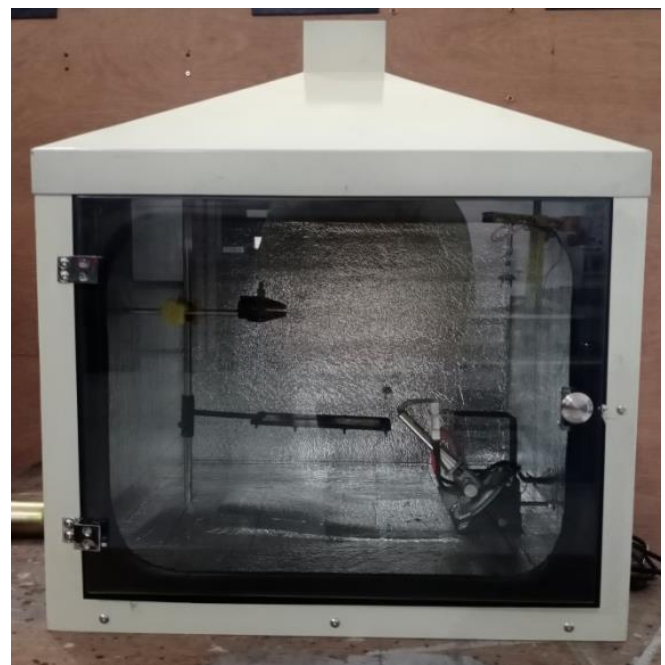

Gambar 1. Alat uji hambat bakar plastik

\section{HASIL DAN PEMBAHASAN}

Pembuatan alat uji laju dan waktu pembakaran plastik berdasarkan pada studi literatur khususnya standar ASTM D-635 dan UL-94 yang digunakan sebagai acuan dalam merancang gambar dan menyusun morfologi. Proses manufaktur dimulai dengan merancang gambar 2 dimensi dan 3 dimensi. Cover plate dibentuk dengan proses bending, sedangkan proses milling dan turning digunakan pada pembuatan part pendukung. Proses penyalaan api dilakukan secara elektronik menggunakan rangkaian Electric Ignition seperti ditunjukkan pada Gambar 2.

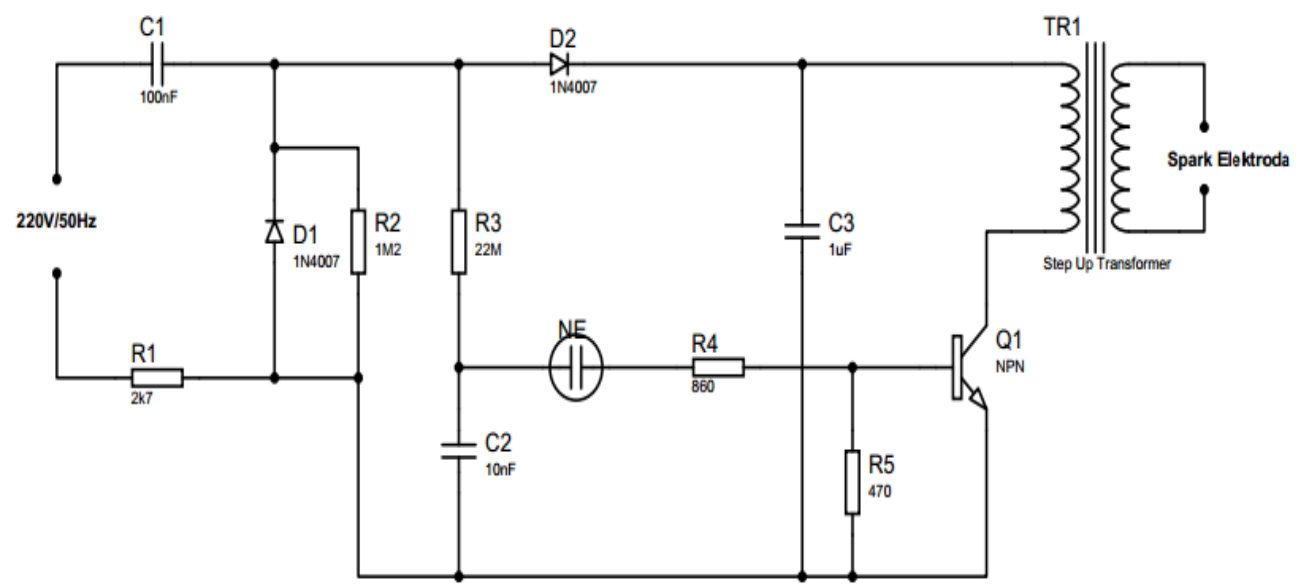

Gambar 1. Skema electric ignition circuit

Prinsip kerja rangkaian ignition ini adalah ketika tegangan $220 \mathrm{~V} / 50 \mathrm{~Hz}$ masuk kedalam rangkaian, maka pada $\mathrm{C} 1$ akan terjadi reaktansi kapasitif sebesar $\mathrm{Xc}=31.847 \Omega$. Sehingga arus yang melewati C1 akan dibatasi oleh Xc. 
Diode D1 berfungsi sebagai clipper negatif sehingga sinyal yang tersisa adalah pada fasa positif saja, sedangkan fasa negatif akan dibuang melalui R1. R2 berfungsi sebagai pemberi beban ringan pada D1 agar kondisi pada D1 selalu terjadi beda potensial. R3 berfungsi sebagai pengatur arus yang masuk pada C2 sehingga waktu titik picu NE dapat diatur sesuai kebutuhan. Ketika tegangan pada C2 mencapi $90 \mathrm{~V}$ yang merupakan tegangan yang menyebabkan NE konduktif, maka secara cepat arus akan mengalir melalui R4 sehingga Q1 menjadi saturasi dan mengakibatkan kumparan primer pada TR1 mendapatkan beda potensial secara cepat. Karena TR1 merupakan transformator step up, maka pada ujung kumparan sekunder akan terjadi lonjakan tegangan hingga $1 \mathrm{kV}$ dan ini mengakibatkan terjadinya percikan api pada kedua ujung elektrodanya. R4 dan R5 membentuk suatu pembagi tegangan agar tegangan dan arus yang masuk pada basis Q1 tidak terlalu besar. D2 pada rangkaian berfungsi sebagai penahan lonjakan tegangan yang terjadi pada kumparan primer TR1 agar tidak masuk kembali ke sumber tegangan saat terjadi pemicuan.C3 berfungsi sebagai penstabil tegangan agar saat terjadi pemicuan pada TR1 tegangan pada kumparan primer tetap stabil sehingga kualitas percikan api pada elektroda akan selalu stabil.

Hasil pengujian dari beberapa spesimen yang membandingkan berapa lama waktu yang dibutuhkan untuk membakar habis spesimen pada panjang $125 \mathrm{~mm}$ dan berapa kali menggeser bunsen burner dengan lama pembakaran 5 detik, dapat dilihat pada Tabel 1 . Dari hasil pengujian yang diperoleh, semakin lama waktu yang dibutuhkan untuk membakar habis spesimen pada jarak 125, maka semakin baik hambat bakar dari spesimen tersebut.

Tabel 1. Data pengujian rambat bakar

\begin{tabular}{cccc}
\hline No. & \multicolumn{1}{c}{ Jenis Spesimen } & Jumlah Pembakaran & Waktu \\
\hline 1 & Komposit 5\% VF Geomaterial & $1 \mathrm{X}$ & 7 menit 5 detik \\
2 & Komposit 5\% VF Geomaterial & $1 \mathrm{X}$ & 7 menit 9 detik \\
3 & Komposit 5\% VF Geomaterial & $1 \mathrm{X}$ & 7 menit 3 detik \\
4 & Komposit 10\% VF Geomaterial & $3 \mathrm{X}$ & 7 menit 25 detik \\
5 & Komposit 10\% VF Geomaterial & $2 \mathrm{X}$ & 7 menit 17 detik \\
6 & Komposit 10\% VF Geomaterial & $3 \mathrm{X}$ & 6 menit 58 detik \\
7 & Spakbor Honda Grand & $1 \mathrm{X}$ & 2 menit 10 detik \\
8 & Spakbor Honda Grand & $1 \mathrm{X}$ & 2 menit 3 detik \\
9 & Spakbor Honda Grand & $1 \mathrm{X}$ & 2 menit 14 detik \\
\hline
\end{tabular}

\section{KESIMPULAN}

Telah dibuat sebuah Alat Uji Hambat Bakar Plastik Sesuai ASTM D635, melalui proses perancangan, perakitan dan finishing dengan baik. Proses perancangan yaitu gambar desain alat uji, proses perakitan meliputi pemasangan statif set, bunsen burner, dan komponen lainya, proses finishing yaitu pengecatan cover alat uji dan komponenkomponen tertentu. Alat yang dibuat telah memenuhi kriteria perancangan baik dari segi fungsi maupun estetika, dengan pematik api otomatis, clamp statif yang terdapat adjuster sehingga ketinggian spesimen dapat diatur dan sliding pada bunsen burner guna 
meminimalisir terbakarnya spesimen sebelum pengujian dimulai. Hasil unjuk kerja menunjukkan bahwa alat yang dibuat daat berfungsi dengan baik.

\section{UCAPAN TERIMA KASIH}

Penulis ingin mengucapkan terima kasih kepada Pusat Penelitian dan Pengabdian Kepada Masyarakat (PPPM) Sekolah Tinggi Teknologi "Warga" Surakarta atas hibah dana Penelitian Lokal Tahun Anggaran 2019.

\section{DAFTAR PUSTAKA}

[1] M.I. Misnon, M.M. Islama, J.A. Epaarachchi, H. Chen, K. Goda, M.T.I. Khan, "Flammability Characteristics Of Chemical Treated Woven Hemp Fabric Reinforced Vinyl Ester Composites", Science And Technology Of Materials, Vol. 30, Pp. 174-188, 2018.

[2] D. Setyanto, Jamasri, B. Suhendro, A.E. Tontowi, "Alumina As A Filler In UPR Matrix For FRP Composite Roofing Sheets", International Journal Of Materials Science, Vol. 7, No. 3, Pp. 191-202, 2012.

[3] ASTM D-638-02 Standart Test Method For Tensile Properties Of Plastics. Philadelphia,PA : American Society For Testing And Material.

[4] ASTM D3801-20a Standard Test Method For Measuring The Comparative Burning Characteristics Of Solid Plastics In A Vertical Position Burning Characteristics. Philadelphia,PA : American Society For Testing And Material.

[5] Basmal, J. Sukarno,Siswanto, "Pengaruh Penguat Hibride Partikel Serbuk Arang Sekam Padi Dan Kalsit Terhadap Sifat Mekanik Pada Komposit Polyester Resin", POLITEKNOSAINS, Vol. XVI, No 1, 2017. 